\title{
Properties of Providence and Proteus morganii Transducing Phages
}

\author{
By J. N. COETZEE, J. A. SMIT AND O. W. PROZESKY \\ Department of Microbiology, University of Pretoria and \\ Atomic Energy Board, Pretoria, South Africa
}

(Received 22 February 1966)

\begin{abstract}
SUMMARY
The properties of three transducing phages derived from providence strains NCTC 9207, 9246, 9290 and phage $M$ derived from Proteus morganii NCTC 10041 are described. The providence phages are present in supernatant fluids of young broth cultures; phage $\mathbf{M}$ is ultraviolet-inducible. The 3 providence phages only attack and transduce into providence strains NCTC 9211, 9295; the action of phage $M$ is restricted to $\boldsymbol{P}$. morganii NCTC 2815. The phages transduce different markers at rates of $3 \times 10^{-7}-1 \times 10^{-6} /$ phage adsorbed and are thus capable of generalized transduction. No abortive transductants were encountered. The providence phages are serologically related. Morphologically the phages resemble the salmonella transducing phage $\mathbf{P} 22$ but phage $\mathbf{M}$ differs in that it possesses a delicate collar round the short neck. The infectivity of the phages is $\mathrm{Ca}^{2+}$ independant. Phage $\mathbf{M}$ is more heat susceptible than the providence phages while its transducing particles are chloroform sensitive. Mutants of providence NCTC 9211, 9295 lysogenized by the phages are competent recipients in transduction experiments, while mutants of strain NCTC 2815 lysogenized by phage $M$ yield no transductants when treated with suitable lysates of this phage. Small doses of ultraviolet irradiation of providence phages increase transduction rates. Phage $\mathbf{M}$ lysates similarly treated show no such stimulation. The phages have deoxyribonucleic acid base compositions similar to the organisms which they transduce and density gradient centrifugation reveals that transducing activity forms single peaks 2 or 3 fractions heavier than corresponding plaque-forming particles.
\end{abstract}

\section{INTRODUCTION}

Proteus and providence organisms display many intra- and inter-group differences (Ewing, 1958) and their classification is uncertain. Rauss (1962) advocated a tribe Proteae with genera Proteus, Morganella, Rettgerella and Providencia; Topley \& Wilson's Principles (1964) excluded providence strains from a genus Proteus limited to 'vulgaris', 'mirabilis', 'morganii' and 'rettgeri' species. In an approach to this problem various gene loci of Proteus mirabilis, $\boldsymbol{P}$. morganii and providence strains are being compared in this laboratory. With the former two organisms biochemical work is complemented with transduction studies using phages previously isolated (Coetzee \& Sacks, 1960; Coetzee, 1966). To apply this technique in the providence work it was decided to search for transducing phages active on members of this group. The present paper describes properties of such phages and additional features of the $\boldsymbol{P}$. morganii (Coetzee, 1966) transducing system. 


\section{METHODS}

Media. In addition to the media previously used (Coetzee \& Sacks, 1960) a minimal medium (Lederberg, 1950) was used for the selection of prototrophic transductants of providence strains. For transduction experiments with Proteus morganii the latter medium was supplemented with $0.0024 \%(\mathrm{w} / \mathrm{v})$ L-cystine, $0.0001 \%(\mathrm{w} / \mathrm{v})$, each, Ca pantothenate and nicotinic acid, according to Porter \& Meyers (1945).

Phages and bacteria. The 23 temperate providence phages previously isolated (Coetzee, 1963a) and the Proteus morganii phage 10041/2815 (Prozesky, De Klerk $\&$ Coetzee, 1965) subsequently called phage M (Coetzee, 1966) were used. The general phage techniques including those of serology and determination of $\mathrm{Ca}^{2+}$ requirements for infectivity were according to Adams (1959). The organisms used for host-range experiments have been described (Coetzee, $1963 a, b, c$ ). Onestep mutants resistant to $1 \mathrm{mg}$. streptomycin sulphate $/ \mathrm{ml}$. (str-r) were obtained as before (Coetzee \& Sacks, 1960) and auxotrophic mutants of providence strains were selected by the penicillin method of Gorini \& Kaufman (1960) after ultraviolet irradiation of washed suspensions to about $1 \%$ survival. Replication was from MacConkey agar to minimal medium; auxotrophs were identified auxanographically (Lederberg, 1950).

Ultraviolet radiation. The Hanovia sterilamp and the methods used to irradiate phage suspensions have been described (Coetzee \& Sacks, 1960).

Preparation of phage lysates. Lysates with plaque-forming titres of about $5 \times 10^{9}$ p.f.u./ml. were prepared by the agar-layer method previously used (Coetzee \& Sacks, 1960). Phage stocks were sterilized by membrane filtration (MF 30 Membranfilter Goettingen) or by adding $\mathbf{0} \cdot \mathbf{1}$ vol. chloroform. Purified preparations with titres of about $1 \times 10^{12}$ p.f.u./ml. were obtained by differential centrifugation according to Prozesky et al. (1965).

Isolation of phage nucleic acid. The method of Mandell \& Hershey (1960) modified by Davidson \& Freifelder (1962) was used.

Isolation of bacterial deoxyribonucleic acid. Bacteria (3-4 g. wet wt.) were lysed with sodium lauryl sulphate and the deoxyribonucleic acid isolated according to Marmur (1961).

Estimation of base composition of deoxyribonucleic acid. Deoxyribonucleic acid was hydrolysed with $90 \%(\mathrm{v} / \mathrm{v})$ formic acid at $175^{\circ}$ for $30 \mathrm{~min}$. (Wyatt, 1955). The bases were then separated on a two-dimensional chromatogram run on Whatman no. 1 paper by a descending technique. The solvents were first isopropanol $+\mathrm{HCl}$ (sp.gr. $1 \cdot 18)+$ water $(170+41+39$ by vol. $)$; then $n$-butanol saturated with water at $23^{\circ}+$ $15 \mathrm{~N}$-ammonium hydroxide $(100+1$ by vol.). The spots were made visible by u.v. irradiation (wavelength $254 \mathrm{~m} \mu$ ), quantitatively eluted and their base content estimated according to Wyatt (1955). Phosphate in nucleic acid preparations was estimated by the method of Bergold \& Pister (1948).

Density gradient centrifugation of phages. A sample $(0 \cdot 3 \mathrm{ml}$.) of phage suspension (about $1 \times 10^{12}$ p.f.u./ml.) was added to $3.0 \mathrm{ml}$. of a caesium chloride solution (Sheppard, 1962). The mixture was centrifuged at $27,000 \mathrm{r.v} . / \mathrm{min}$. for $18 \mathrm{hr}$ in a Spinco model L preparative centrifuge with swinging-bucket rotor no. SW-39. Single drops were collected in $2 \mathrm{ml}$. broth from the bottom of the centrifuge tube 
after puncture with a no. 22 syringe needle. The fractions were assayed for infective centres and transducing particles.

Electron microscopy. This was done as for proteus phages by the methods of Prozesky et al. (1965).

Transduction techniques. The 23 providence phages were screened for ability to transduce the str- $r$ marker. The adsorption mixtures and controls were constituted as before (Coetzee \& Sacks, 1960). After $20 \mathrm{~min}$, at $30^{\circ}$ the mixtures (or samples) were filtered through membrane filters (Iyer, 1962). The membranes were incubated on nutrient agar for $4 \mathrm{hr}$ to allow for delay in phenotypic expression of the marker (Coetzee \& Sacks, 1960) before transfer to the surface of MacConkey agar containing $1 \mathrm{mg}$. streptomycin sulphate $/ \mathrm{ml}$. Colonies were scored after $48 \mathrm{hr}$ at $37^{\circ}$. With transductions of prototrophy to auxotrophic mutants the bacteria in adsorption mixtures were deposited by centrifugation after $20 \mathrm{~min}$. The deposit was suspended in saline and samples plated on minimal media.

\section{RESULTS}

Three of the 23 temperate providence phages were able to transduce the $s t r-r$ marker, The phages PL25, PL26, PL37 were present in the supernatant fluids of overnight broth cultures of providence strains NCTC 9207, 9246, 9290 respectively (Coetzee, 1963a). These 3 providence strains can be distinguished by means of their susceptibility to a series of lytic phages (Coetzee, unpublished results). These phages have identical host-ranges limited to providence NCTC 9211, 9295, on which they have equal efficiencies of plating and into which they transduce markers at about $3-9 \times 10^{-7} /$ adsorbed phage. Strains NCTC 9211,9295 have the same biochemical reactions and belong to providence biogroup 1 (Ewing, 1958). These strains can be distinguished by their reactions to the series of phages mentioned above. Phages PL 25, PL 26, PL 37 had no action on any of the other strains of the family Enterobacteriaceae examined. Recipient controls in transduction experiments had less than 10 colonies on the membranes as compared with hundreds on test filters. Phage controls were sterile and transduction rates were not affected by previous treatment of phage lysates with chloroform or deoxyribonuclease (Coetzee $\&$ Sacks, 1960). Addition of potent antiphage serum, completely absorbed with recipient organisms, drastically decreased the transducing ability of phage suspensions. Phage M lysates differ from these providence phages in that the transducing particles of the former are sensitive to chloroform. Two days after chloroform treatment the transduction rate of the str-r marker had decreased from $1 \times 10^{-6}$ to $5 \times 10^{-9} /$ phage particle adsorbed, whereas the plaque-forming titre decreased by a factor of 2 .

The 3 providence phages are more heat resistant than phage M. They undergo $95 \%$ inactivation at $70^{\circ}$ for $15 \mathrm{~min}$. as compared with $99.9 \%$ for the latter phage (Coetzee, 1966). Like phage M (Coetzee, 1966) the infectivity of the providence phages is $\mathrm{Ca}^{2+}$ independent. There was no difference between control titres and the titres recorded in the presence of $0.01 \mathrm{M}$-sodium citrate. Some of these data are presented in Table 1 . The providence phages are related serologically but are distinct from phage $M$ ('Table 2 ).

The morphology of the providence transducing phages is shown in $\mathrm{Pl}$. 1. They 
possess polyhedral contours, short necks and base plates with a number of pins. Their average measurements are identical. The inter-apex length is $600 \AA$, tail length $160 \AA$ and the base plate width is $210 \AA$. They lack the collar of phage $M$ (Prozesky et al. 1965) and resemble salmonella transducing phage P 22 (Anderson, 1960). Many of the capsids have an uneven rough appearance, suggestive of arrays of capsomeres; but neither the shape nor the packing arrangements of the latter could be determined. A short rod about $30 \AA$ wide was sometimes seen projecting beyond the base plate of phage PL26 (Pl. 1, fig. 2). It may be nucleic acid; similar structures have been encountered with two non-transducing providence phages

Table 1. Properties of providence and Proteus morganii transducing phages

\begin{tabular}{|c|c|c|c|c|c|c|}
\hline Phage & $\begin{array}{l}\text { Derived } \\
\text { from NCTC }\end{array}$ & $\begin{array}{l}\text { Indicator } \\
\text { and } \\
\text { transduces } \\
\text { into } \\
\text { NCTC no. }\end{array}$ & $\begin{array}{c}\mathrm{CHCl}_{3} \\
\text { sensitivity } \\
\text { of } \\
\text { transducing } \\
\text { particles }\end{array}$ & $\begin{array}{l}\text { Transduction rate/ } \\
\text { adsorbed phage }\end{array}$ & $\begin{array}{c}\mathrm{Ca}^{2+} \\
\text { infectivity } \\
\text { dependance }\end{array}$ & $\begin{array}{c}\% \\
\text { inactivation } \\
70^{\circ} \\
15 \mathrm{~min} .\end{array}$ \\
\hline PL25 & 9207 & $\begin{array}{l}9211 \\
9295\end{array}$ & - & 3 to $9 \times 10^{-7}$ & - & 95 \\
\hline PL26 & 9246 & 9295 & - & 3 to $9 \times 10^{-7}$ & - & 95 \\
\hline PL37 & 9290 & 9295 & - & 3 to $9 \times 10^{-7}$ & - & 95 \\
\hline $\mathbf{M}$ & 10041 & 2815 & + & $1 \times 10^{-6}$ & - & $99 \cdot 9$ \\
\hline
\end{tabular}

Table 2. Neutralization constants of providence and Proteus morganii phage antisera

Dilutions of phage antisera were mixed with the phages at $37^{\circ}$. Phage was assayed at intervals. The proportion of surviving phage was plotted against time. Survivals were first-order reactions from which neutralization constants were calculated.

\begin{tabular}{|c|c|c|c|c|}
\hline & \multicolumn{4}{|c|}{ Phage } \\
\hline & PL 25 & PL 26 & PL37 & $\mathbf{M}$ \\
\hline & \multicolumn{4}{|c|}{ Neutralization constants (min..$^{-1}$ ). } \\
\hline Anti-PL 25 & 120 & 30 & 20 & 0 \\
\hline Anti-PL26 & 20 & 110 & 10 & 0 \\
\hline Anti-PL37 & 10 & 20 & 180 & 0 \\
\hline Anti-M & $\mathbf{0}$ & 0 & 0 & 80 \\
\hline
\end{tabular}

(Prozesky et al. 1965) which have similar morphologies. Clostridium perfringens phage 80 (Vieu, Guélin \& Dauguet, 1965) also has a structure which projects beyond the base plate; it is $65 \AA$ in width and can be consistently demonstrated. It is thought to be a tail core.

A large number of different auxotrophs of providence strains NCTC 9211, 9295 were obtained. A few, 9211 hi-2, try-1, 9295 ad-4, cys-10, leu-1 were selected for use because of their low revertant rates. These auxotrophs were transduced to prototrophy by the three providence phages produced on wild strains NCTC nos. 9211, 9295 or on other auxotrophs. The rates of transduction are similar to those of the $s t r-r$ marker. No abortive transductants were detected.

No attempts were made to prevent secondary lysogenization of transduced clones (Coetzee \& Sacks, 1960) and all colonies examined were lysogenized by the phage and resistant to lysis by any of the three providence phages. Unlike the Proteus mirabilis (Coetzee \& Sacks, 1960; Coetzee, 1961; Böhme, 1963) and $P$. 
morganii (Coetzee, 1966) systems, lysogenized providence prototrophic transductants which originated from auxotrophic recipients still yielded str-r transductants (albeit at lower rates) when treated with lysates prepared on $s t r-r$ variants. This property allows a nice distinction to be made between the 3 providence phages (Table 3). Many other phages can transduce recipients previously lysogenized by them like P22 (Yura, 1956), P1 (Arber, 1960), B 3, F 116 (Holloway, Monk, Hodgins $\&$ Fargie, 1962) $\lambda$ (Weigle 1957), $\phi 80$ (Matsushiro, Sato \& Kida, 1964).

Table 3. Transduction to streptomycin resistance of NCTC 9211 and prototrophic NCTC 9211 hi-2 transductants lysogenized with phages PL25, PL26, PL3\%, respectively

In separate experiments NCTC 9211 hi-2 was transduced to prototrophy by phages PL 25, PL 26 and PL 37, produced on NCTC 9295 str-r. Prototrophic transductant clones were picked off and demonstrated to be lysogenized by the corresponding phage. These transductants are written 9211 (PL 25), etc. Using these lysogenic transductants and the wild strain NCTC 9211 quantitative transduction experiments were done with the phage lysates previously used and selection for str-r transductants.

\begin{tabular}{lccc} 
Recipients & \multicolumn{3}{c}{ Phages } \\
\cline { 2 - 4 } NCTC no. & PL25 & PL26 & PL 37 \\
9211 (PL 25) & $811^{*}$ & 700 & 526 \\
9211 (PL 25) & 325 & 371 \\
9211 (PL 26) & 400 & 73 & 311 \\
9211 (PL 37) & 327 & 361 & 49
\end{tabular}

* No. str-r transductants.

\section{Table 4. Base composition of deoxyribonucleic acids of phages and bacteria}

Deoxyribonucleic acid isolated from phage or organisms was hydrolysed with formic acid and the bases separated by paper chromatography in two dimensions. Ultraviolet absorbing areas were removed from the paper and eluted with $0 \cdot 1 \mathrm{~N}-\mathrm{HCl}$. The concentration of each base was quantitatively determined from its molar extinction coefficient.

\begin{tabular}{|c|c|c|c|c|c|c|c|}
\hline \multirow[b]{2}{*}{ Source of DNA } & \multirow{2}{*}{$\begin{array}{c}\text { No. } \\
\text { analyses }\end{array}$} & \multicolumn{4}{|c|}{$\begin{array}{l}\text { Mean base content } \\
\text { (moles/100 moles) }\end{array}$} & \multirow{2}{*}{$\begin{array}{l}\text { Guanine } \\
+ \text { cytosine } \\
\text { (moles/ } \\
100 \text { moles) }\end{array}$} & \multirow{2}{*}{$\begin{array}{c}\text { Total bases } \\
\text { /phosphor- } \\
\text { us (moles/ } \\
\text { g. atom) }\end{array}$} \\
\hline & & Adenine & Thymine & Guanine & Cytosine & & \\
\hline Phage $\mathbf{M}$ & 7 & $25 \cdot 7$ & $25 \cdot 4$ & $24 \cdot 6$ & $24 \cdot 3$ & $48 \cdot 9$ & 97 \\
\hline Phage PL26 & 4 & $29 \cdot 6$ & $28 \cdot 8$ & $21 \cdot 0$ & $20 \cdot 6$ & $41 \cdot 6$ & 99 \\
\hline NCTC 2815 & 4 & $25 \cdot 2$ & $25 \cdot 4$ & $24 \cdot 5$ & $24 \cdot 9$ & $49 \cdot 4$ & 99 \\
\hline NCTC 9295 & 4 & $29 \cdot 3$ & $29 \cdot 5$ & $20 \cdot 6$ & $20 \cdot 6$ & $41 \cdot 2$ & 98 \\
\hline
\end{tabular}

The differential effect of ultraviolet irradiation on the plaque-forming and transducing abilities of phages PL 26 and M is illustrated in Fig. 1. The effect of this treatment on the transduction rate of phage PL 26 is similar to that on phages PL 25, PL 37 and Proteus mirabilis transducing phages (Coetzee \& Sacks, 1960) and many other transducing phages (Holloway et al. 1962). The initial stimulation in transduction frequency with PL26 was encountered for all three markers (str-r, $a d-4, h i-2)$ tested. The behaviour of phage $\mathrm{M}$ was different. The transduction frequency of $a d-1, t r y-1, h i-1$, str-r (Coetzee, 1966) progressively decreased with time of irradiation of phage $\mathbf{M}$. In this respect phage $\mathbf{M}$ resembles the Pseudomonas aeruginosa phage F116 (Holloway et al. 1962). Fig. 1 also shows that the plaqueforming ability of phage $\mathbf{M}$ was inactivated at a greater rate than that of phage PL 26. 
The deoxyribonucleic acid base composition of phage $\mathbf{M}$, its recipient in transduction experiments Proteus morganii NCTC 2815, phage PL 26 and one of its indicator organisms providence strain NCTC 9295 are given in Table 4. Each phage and host have practically the same guanine + cytosine molar content. Transducing phages $\lambda$ (Schildkraut, Marmur \& Doty, 1962) and P22 (Sinsheimer, 1960) also have the same base compositions as their bacterial partners. Exceptions are encountered with the Bacillus subtilis transducing phages where the nucleic acid of phage SP10 (Okubo, Stodolsky, Bott \& Strauss, 1963) differs physically from that of its host, and phage PBS 2 has a deoxyribonucleic acid which does not resemble that of B. subtilis chemically or in base content (Mahler, Cahoon \& Marmur, 1964). The guanine + cytosine values obtained for the $\boldsymbol{P}$. morganii and providence strains by the chemical,

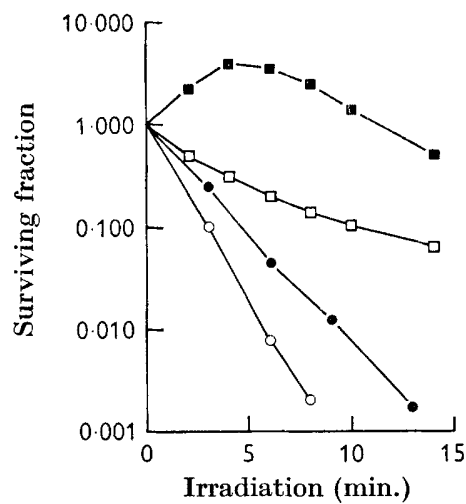

Fig. 1

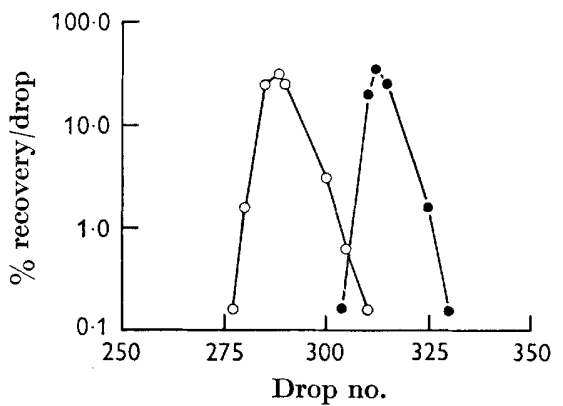

Fig. 2

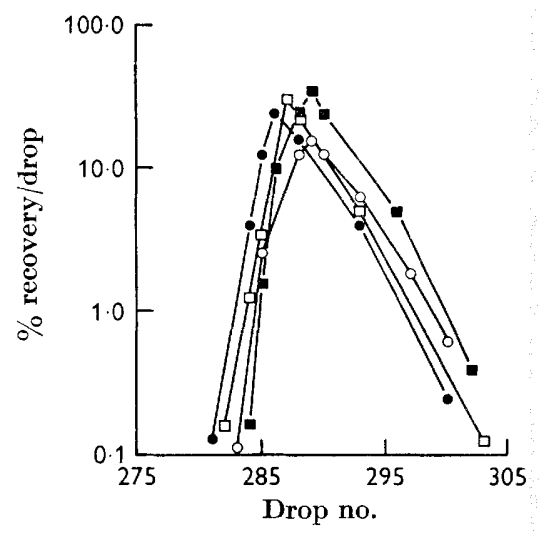

Fig. 3

Fig. 1. Effect of ultraviolet irradiation on plaque-forming and transducing abilities of phages PL 26 and $M$ produced on NCTC 9295, and 2815. Lysates were irradiated at $10 \mathrm{ergs} / \mathrm{min} .{ }^{2} / \mathrm{sec}$. At intervals samples were removed and used in quantitative transduction experiments with auxotrophs as recipients. The plaque-forming ability of the samples was also determined. Phage PL 26: - - plaque formation; - - N-, NCTC 9295, ad-4 transductions to prototrophy. Phage M: $-\mathrm{O}-$, plaque formation; - $\square-$, NCTC 2815, $h i-1$ transductions to prototrophy.

Fig. 2. Separation of phages PL 25 and $\mathrm{M}$ by $\mathrm{CsCl}$ density-gradient centrifugation. A 3 ml. sample of a mixture of lysates was centrifuged and 4.20 drops collected in tubes containing $1 \mathrm{ml}$. broth, one drop/tube. The plaque-forming titre of the contents of tubes was assayed on NCTC strains 9211, 2815. Phage M, 一O-; phage PL 25, - - -

Fig. 3. Separation of infective and transducing particles of phage PL 25 by density-gradient centrifugation. Phage PL 25 was prepared on strain NCTC 2925 str-r. A $3 \mathrm{ml}$. sample of phage and $\mathrm{CsCl}$ was centrifuged and 390 drops collected in tubes containing $2 \mathrm{ml}$. broth, one drop/tube. The plaque-forming and transducing titres were determined for the contents of tubes. Transductions of NCTC 9295 to $s t r-r-1-$, transduction of NCTC $9211 h i$ - 2 and $t r y-1$ to prototrophy - $\bigcirc-$, - $\square$-, respectively. Plaque-formation, $-\square-$.

methods used here correspond closely to the figures recorded by Falkow, Ryman \& Washington (1962) for other strains of these organisms, which were determined by thermal denaturation of their deoxyribonucleic acids.

Figure 2 shows the distribution of particles collected after $18 \mathrm{hr}$ centrifugation from a mixture of phages $M$ and PL 25. Each phage gives a distinct band and single peak of activity with the former displaced to the heavy side. The recovery of both phages was always above $90 \%$. Activities for transduction to wild type of NCTC 9211 $h i$-2, try-1 and NCTC 9295 to str-r by centrifugal fractions of phage PL 25 are pre- 
sented in Fig. 3. Recovery of transducing particle input varied from about $60 \%$ to more than $90 \%$, depending on the marker used. The curves are similar and show that transductions registered as single peaks coincident with, or up to 3 fractions more dense than, those of infectious centres. Experiments were also done with phage $\mathbf{M}$ samples transducing str-r or prototrophy to strain NCTC 2815 ad-1. Results were similar to those obtained with phage PL25. Transducing activity for the two markers coincided in a peak three drops more dense than the corresponding plaqueforming summit. The above results were reproduced with three independently prepared phage stocks of PL25 and two stocks of phage M. These results resemble those obtained with transducing phage P1 (Ting, 1962) and P22 (Sheppard, 1962). With the Bacillus subtilis transducing phage SP10 (Okubo et al. 1963) the curves representing the two types of activity were also single-peaked but were clearly separated by a number of fractions. Curves obtained here differ markedly from results recorded with Escherichia coli phages $\lambda$ (Weigle, 1961) and $\phi 80$ (Matsushiro et al. 1964). Low frequency of transduction lysates of these phages exhibited a broader density band than the corresponding plaque-forming particles with several peaks or humps.

\section{DISCUSSION}

The three serologically related and very similar providence phages described here can transduce many different regions of the donor chromosome. They are thus capable of gernalized transduction (Campbell, 1964) like phage M (Coetzee, 1966). The rates of transduction correspond to those of other phages able to produce this type of transduction (Coetzee \& Sacks, 1960; Hayes, 1964). As with the Pseudomonas aeruginosa (Holloway \& Monk, 1959), Staphylococcus pyogenes (Edgar \& Stocker, 1961). Proteus mirabilis (Coetzee, 1963d), P. morganii (Coetzee, 1966) and Bacillus subtilis (Thorne, 1962) transducing systems, no abortive transductants (Ozeki, 1956) were observed.

The finding of Holloway et al. (1962) and Prozesky \& Coetzee (1966) that ultraviolet irradiation of Pseudomonas aeruginosa phage F116 and Proteus mirabilis phage 34/13 decreased the frequency of joint transductions may be taken in support of the theory (Jacob \& Wollman, 1958) that this irradiation increases the frequency of exchange between the exogenote and bacterial chromosome. On these grounds the action of ultraviolet radiation on phage $M$ transductions in decreasing the recovery of selected markers could be explained (Holloway et al. 1962) by assuming that phage $\mathbf{M}$ carries larger segments of bacterial chromosome than the providence phages and other phages which show an increased frequency of transduction with low doses of radiation. Unfortunately no joint transduction of markers has yet been found in the systems described here. Apart from the differential effect which ultraviolet radiation has on the plaque-forming and transducing properties of phage $M$ lysates, chloroform affects the latter activity much more than the former property. Wilson (1960) encountered a similar phenomenon with Escherichia coli phage $\mathbf{P} 1$.

With the $\lambda$ and P1 phage Escherichia coli transducing systems there is evidence (Campbell, 1957; Adams \& Luria, 1958; Okubo et al. 1963) that markers from the donor bacterium replace homologous portions of phage chromosomes 'in some 
kind of hybridization process' (Campbell, 1964) to form transducing particles. Because of the close correspondence of deoxyribonucleic acid base composition between phages and bacterial partners described here, it is possible that donor fragments are also integrated into the transducing phage chromosome by a process of substitution similar to that proposed for the $E$. coli systems (Hayes, 1964; Mahler et al. 1964). In Bacillus subtilis transducing systems, where there may not be enough genetic homology between phage and bacterium to allow pairing (Meynell, 1964) there is physical evidence (Okubo et al. 1963; Mahler et al. 1964) that here the bacterial donor fragments are not integrated into the viral chromosome but are packaged into the capsids of transducing particles by a process analogous to phenotypic mixing suggested by Zinder (1953).

In contrast to the distinction obtained between transducing and lytic particles by radiation and chloroform treatments, these two types of particle band very closely with single peaks in $\mathrm{CsCl}$ gradients of the lysates. These results may mean that, unlike $\lambda$ (Weigle, 1961) and phage $\phi 80$ (Matsushiro et al. 1964) the providence and Proteus morganii transducing phages are formed by the bacterial donor fragment replacing a phage segment of nearly equal size. It was hoped to show that at least one of the temperate providence phages examined with activity extending to other members of the Proteus group (Coetzee, 1963 $a$ ) would prove capable of transduction. As in the case of the $\boldsymbol{P}$. mirabilis (Coetzee, $1963 d$ ) and $\boldsymbol{P}$. morganii systems (Coetzee, 1966) the transducing phages discovered here have a very restricted host-range which excludes the possibility of inter-species hybridization.

One of us (J. N. C.) is in receipt of grants from the South African Council for Scientific and Industrial Research.

\section{REFERENCES}

Adams, J. N. \& Luria, S. E. (1958). Transduction by bacteriophage P1: abnormal bacteriophage function of the transducing particles. Proc. natn. Acad. Sci., U.S.A. 44, 590.

Adams, M. H. (1959). Bacteriophages. New York: Interscience Publishers, Inc.

Anderson, T. F. (1960). On the fine structure of the temperate bacteriophages P1, P2, and P22. Proc. Eur. Reg. Conf. electron microscopy, 2, 1008.

Arber, W. (1960). Transduction of chromosomal genes and episomes in Escherichia coli. Virology, 11, 273.

Bergold, G. \& Pister, L. (1948). The quantitative micro-determination of deoxy- and ribonucleic acids. $Z$. Naturf. $3 b, 406$.

Böнмe, H. (1963). Transduction of prototrophy to auxotrophic mutants of Proteus mirabilis. Biochem. biophys. Res. Comm. 10, 60.

Campbeix, A. (1957). Transduction and segregation in Escherichia coli $\mathrm{k} 12$. Virology, 14, 366.

Campbeit, A. (1964). Transduction. In The Bacteria. Ed. by I. C. Gunsalus and R. Y. Stanier, vol. 5, p. 49. New York: Academic Press Inc.

Coetzee, J. N. (1961). Lysogenic conversion in the genus Proteus. Nature, Lond. 189, 946.

Coetzee, J. N. (1963a). Lysogeny in Providence strains and the host-range of Providence bacteriophages. Nature, Lond. 197, 515.

Coktzee, J. N. (1963b). Lysogeny in Proteus rettgeri and the host-range of $\boldsymbol{P}$. rettgeri and $P$. hauseri bacteriophages, J. gen. Microbiol. 31, 219.

Coetzee, J. N. $(\mathbf{1 9 6 3}$ c). Host-range of Proteus morganii bacteriophages. Nature, Lond. $199,827$. 
Coetzee, J. N. (1963d). Transduction of swarming in Proteus mirabilis. J. gen. Microbiol. 33, 1.

Coetzee, J. N. (1966). Transduction in Proteus morganii. Nature, Lond. 210, 220.

Coetzee, J. N. \& SAcks, T. G. (1960). Transduction of streptomycin resistance in Proteus mirabilis. J. gen. Microbiol. 23, 445 .

Davidson, P. F. \& Freifelder, D. (1962). The physical properties of the deoxyribonucleic acid from T 7 bacteriophage. J. mol. Biol. 5, 643.

Edgar, J. B. \& Stocker, B. A. D. (1961). Metabolic and genetic investigations of nutritionally exacting strains of Staphylococcus pyogenes. Nature, Lond. 191, 1121.

Ewing, W. H. (1958). The nomenclature and taxonomy of the Proteus and Providence groups. Int. Bull. bact. Nomencl. Taxon. 8, 17.

Falkow, S., Ryman, I. R. \& Washington, O. (1962). Deoxyribonucleic acid base composition of Proteus and Providence organisms. J. Bact. 83, 1318.

Gorini, L. \& KaUfman, H. (1960). Selecting bacterial mutants by the penicillin method. Science, 131, 604.

HAYES, W. (1964). The Genetics of Bacteria and their Viruses. Oxford: Blackwell Scientific Publications.

Holloway, B. W. \& Monk, M. (1959). Transduction in Pseudomonas aeruginosa. Nature, Lond. 184, 1426.

Holloway, B. W., Monk, M., Hodgins, L. \& Fargie, B. (1962). Effects of radiation on transduction in Pseudomonas aeruginosa. Virology, 18, 89.

Iyer, V. N. (1962). Application of the membrane filter for the quantitative study of transformations with particular reference to phenotypic expression of an erythromycinresistance mutation. $J$. Bact. 84, 326.

JACOB, F. \& Wollman, E. L. (1958). Genetic and physical determinations of chromosomal segments in Escherichia coli. Symp. Soc. exp. Biol. 12, 75.

LEDERBERG, J. (1950). Isolation and characterization of biochemical mutants of bacteria. Meth. Med. Res. 3, 5.

Mahler, I., Cahoon, M. \& Marmur, J. (1964). Bacillus subtilis deoxyribonucleic acid transfer in PBS 2 transductions. J. Bact. 87, 1423.

Mandell, J. D. \& Hershey, A. D. (1960). A fractionating column for analysis of nucleic acids. Analyt. Biochem. 1, 66.

Marmur, J. (1961). A procedure for the isolation of deoxyribonucleic acid from microorganisms. J. mol. Biol. 3, 208.

Matsushiro, A., Sato, K. \& Kida, S. (1964). Characteristics of the transducing elements of bacteriophage $\phi 80$. Virology, 23, 299.

Meynell, E. (1964). The significance of bacteriophage in bacterial classification. A review. J. gen. Microbiol. 36, 461.

Okubo, S., Stodolsky, M., Botт, K. \& Strauss, B. (1963). Separation of transforming and viral deoxyribonucleic acids of a transducing bacteriophage of Bacillus subtilis. Proc. natn. Acad. Sci., U.S.A. 50, 679.

OzFik, H. (1956). Abortive transduction in purine-requiring mutants of Salmonella typhimurium. Genetic Studies with Bacteria. Publ. Carneg. Instn., no. 612, p. 97.

Porter, J. R. \& Meyers, F. P. (1945). Amino acid interrelationships in the nutrition of Proteus morganii. Arch. Biochem. 8, 169.

Prozesky, O. W. \& Coetzee, J. N. (1966). Linked transduction in Proteus mirabilis. Nature, Lond. 209, 1262.

Prozesky, O. W., De Klerk, H. C. \& Coetzee, J. N. (1965). The morphology of Proteus bacteriophages. J. gen. Microbiol. 41, 29.

Rauss, K. (1962). A proposal for the nomenclature and classification of the Proteus and Providence groups. Int. Bull. bact. Nomencl. Taxon. 12, 53.

Schildkraut, C. L., Marmur, J. \& Doty, P. (1962). Determination of the base composition of deoxyribonucleic acid from its buoyant density of CsCl. J. mol. Biol. 4, 430 .

Sheppard, D. E. (1962). Density gradient centrifugation of bacteriophage P22. Virology, $17,212$.

Sinsheimer, R. L. (1960). The nucleic acids of the bacterial viruses. In The Nucleic Acids, Ed. by E. Chargaff and J. N. Davidson, vol. 3, p. 187. New York: Academic Press Inc. 
Thorne, C. B. (1962). Transduction in Bacillus subtilis. J. Bact. 83, 106.

Ting, R. C. (1962). 'The specific gravity of transducing particles of bacteriophage $\mathbf{P} 1$. Virology, 16, 115.

Topley and Wilson's Principles of Bacteriology and Immunity. (1964). 5th ed. Ed. by G. S. Wilson and A. A. Miles. London: Edward Arnold.

Vieu, J. F., Guélin, A. \& Dauguer, C. (1965). Morphologie du bactériophage 80 de Welchia perfringens. Ann. Inst. Pasteur, 109, $15 \%$.

Weigle, J. (1957). Transduction by coliphage $\lambda$ of the galactose marker. Virology, 4, 14.

Weigle, J. (1961). Densities of transducing $\lambda$ bacteriophage. J. mol. Biol. 3, 393.

Wilson, D. E. (1960). The effects of ultraviolet light and ionizing radiation on the transduction of Escherichia coli by phage P1. Virology, 11, 533.

WYATt, G. R. (1955). Separation of nucleic acid components by chromatography on filter paper. In The Nucleic Acids, ed. by E. Chargaff and J. N. Davidson, vol. 1, p. 243. New York: Academic Press Inc.

YuRA, T. (1956). Evidence of nonidentical alleles in purine-requiring mutants of Salmonella typhimurium. Genetic Studies with Bacteria. Publ. Carneg. Instn., no. 612, p. 63.

ZiNDER, N. D. (1953). Infective heredity in bacteria. Cold Spring Harb. Symp. quant. Biol. $18,261$.

\section{EXPLANATION OF PLATE}

The magnification in all figures is $\times \mathbf{2 7 0 , 0 0 0}$. All phages in ammonium acetate and phosphotungstate. Fig. 1, phage PL 26; fig. 2, phage PL 26; fig. 3, phage PL37; fig. 4, phage PL25. 

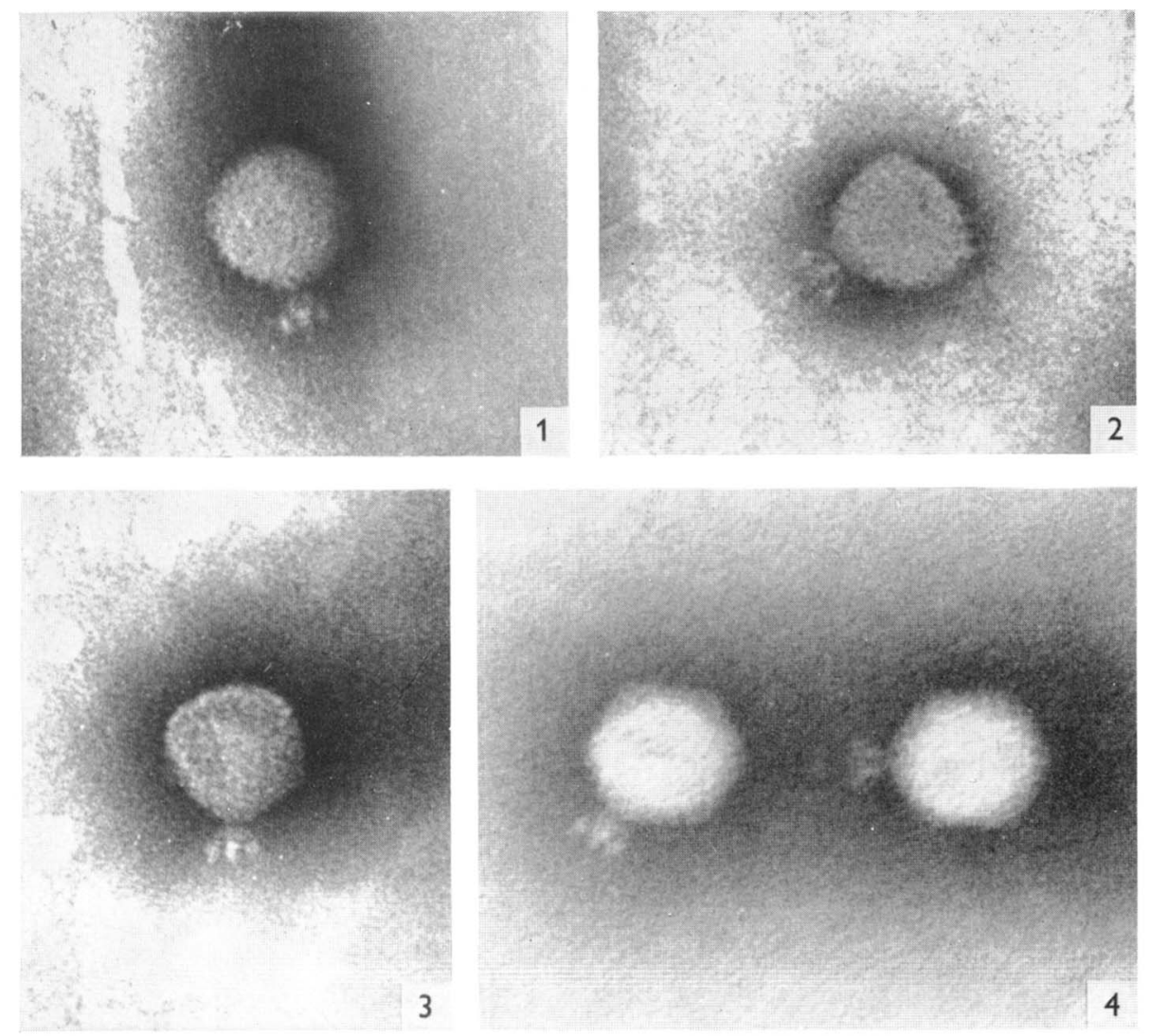